\title{
The Evaluation of the Lucky Component of Open-End Fund Performance Based on Bootstrap Method
}

\author{
Shili Yan \\ School of Economics, Jinan University, Guangzhou, China \\ Email: avrilyans1@163.com
}

How to cite this paper: Yan, S. L. (2020). The Evaluation of the Lucky Component of Open-End Fund Performance Based on Bootstrap Method. American Journal of Industrial and Business Management, 10, 1039-1057.

https://doi.org/10.4236/ajibm.2020.105069

Received: April 26, 2020

Accepted: May 26, 2020

Published: May 29, 2020

Copyright $\odot 2020$ by author(s) and Scientific Research Publishing Inc. This work is licensed under the Creative Commons Attribution International License (CC BY 4.0).

http://creativecommons.org/licenses/by/4.0/

\section{(c) (i) Open Access}

\begin{abstract}
Since the establishment of the first open-end fund in 2001, the development of China's fund industry has never stopped. In the development process of nearly 20 years, people pay attention to the problems related to the fund, which are always the same in many fund products, how to identify the value of investment, which can make investors' investment income optimal, and how to evaluate the fund's performance. It is very important to evaluate the return of the fund. But in fact, the performance of the open-end fund is mainly affected by the fund manager and the fund's own luck. The evaluation of the fund needs a more complete and comprehensive consideration. Based on some fund performance evaluation literature at home and abroad, this paper studies the large-scale stock fund in China, divides the sample database into index fund and active fund, and observes the influence of fund's luck component on their performance respectively, and uses three models to fit, in order to consider the different ways of market interpretation of different models Different explanations of fund performance luck. The bootstrap method is used to simulate the effect of luck component of fund performance. Based on the four-factor model of Carhart, the sustainability of fund performance is considered by alpha ranking method. According to the empirical situation of the two kinds of funds, this paper analyzes the technical situation of the fund managers and the actual impact of fortuitous factors on the fund performance level, and then puts forward relevant suggestions for the participants of the fund market.
\end{abstract}

\section{Keywords}

Open-End Fund, Fund Performance, Bootstrap Method

\section{Introduction}

In the current public fund market, the main reason is that the stock fund can 
bring more excess returns, which is one of the factors considered in determining the scope of fund research. In addition, there are many researches on fund performance at home and abroad for active funds, but few for index funds. This paper makes the same empirical analysis on both types of funds, but the stock index funds are the main part of the sample. Index fund is more controllable for small and medium-sized investors, and requires less professional skills, so the effect is broader.

Through the performance evaluation of open-end stock funds, the main factors reflecting the fund's excess return are measured, which can make investors obtain more practical financial tools, provide more rational reference for them in pursuit of higher excess return, and then reduce investment risk. And for fund companies and fund managers, accurate evaluation of fund performance can also make them provide reference opinions when designing fund products and making investment direction, and then adjust investment plans to obtain higher returns. Furthermore, for the whole securities market, the correct analysis of the performance characteristics of the fund can also provide reference for the government to formulate and issue reasonable relevant policies, and then achieve effective supervision of the market, and promote the healthy development of China's securities market.

The structure of this paper is first through the performance evaluation methods of open-end funds and the research of fund performance affected by luck, then builds a model to understand the situation of China's open-end fund market. In this paper, CAPM model, FFC four-factor model and CPZ seven-factor model are used to study the fund performance. Then, bootstrap method is used to study the luck component of fund performance and discuss the influence of luck and technology on fund performance.

\section{Literature Review}

The evaluation of the overall performance of the fund is mainly based on some performance evaluation indicators, such as the return on equity of the fund without risk adjustment and some indexes with risk adjustment, such as Treynor index, sharp index and Jason index, which are constructed as indicators to measure the performance level of the fund. CAPM, a capital asset pricing model put forward by Sharpe (1966), is an important foundation for the development of modern financial field, which makes the performance evaluation and attribution of funds change from qualitative analysis to quantitative analysis. Fama (1972) thinks that the excess return rate can be considered from another perspective, that is, from the whole to the part, the excess return rate of asset portfolio can be divided as follows: one is its risk tolerance, because of the positive correlation between risk and return, it is expressed by the risk return rate plus; the other is the selection return rate, that is, the selection ability of securities. At the same time, they believe that risk tolerance can also be divided into the next two steps, the two parts are the risk tolerance of two parties-investors and fund 
managers; the securities selection ability is divided into net selection ability and decentralization ability. Fama and French (1993) found that beta factor can not fully explain the excess return of the fund in the classical CAPM model through the fund data of NYSE, so they added scale factor and book to market ratio factor on the basis of CAPM to further explain the return of the fund, analyze the impact of each factor on the return and the relevant relationship. This is Fama French three-factor model. In China, on the basis of Fama French three-factor model, Carhart (1997) put forward the momentum factor, which was proved to have a certain explanatory effect on the fund's income difference by combining with the monthly return data of the US fund market, and made up for the deficiency of the three-factor model in explaining the trend effect. Therefore, the Fama French Carhart model was formed by adding momentum factor to the Fama French three-factor model, the four-factor model, FFC model for short, is the benchmark model to study the modern financial market. This paper mainly uses the four-factor model to study the fund performance level.

In addition, there are some models which are constructed to divide the performance level of the fund in detail to evaluate the performance of the fund. Henriksson and Merton (1981) think that to measure the timing ability of fund managers, we can assume that factor B in CAPM model can take different values according to different market trends, so they introduce double B and dummy variable D, and build HM model based on CAPM model. Through the analysis of previous cases, they think that from the perspective of HM model, there is no data to prove, In the process of actual investment, fund managers have shown significant opportunity selection ability; Chang \& Lewellen (1984) established $\mathrm{C}-\mathrm{L}$ model with the help of HM model on the basis of apt pricing theory; Brinson, Hood, and Beebower (1986) found another way, not according to CAPM model, but established a $\mathrm{BHb}$ model involving only single period and multi period yield. In this model, the source of income of actively managed funds is divided into three parts: timing effect, securities allocation effect and their interaction effect. The model is more simple and intuitive.

At present, there is no uniform standard method for the research of fund performance sustainability, and the standards for duration are different. Different performance indicators, research intervals and research methods will have different effects on the sustainability of fund performance.

With the gradual elaboration of the research on fund performance level, relevant scholars began to consider the real situation of fund performance. In terms of research methods, we no longer only consider the economic model, plus the application of statistical hypothesis test and other related theories and methods, to simulate and test the fund performance level, and then find the real fund performance distribution. Discussing the impact of luck on the performance of active funds has always been a major aspect of open-end fund performance evaluation, such as Fama and French (2010), Kosowski, Timmermann, Wermers, and White (2006), and Barras, Scaillet, and Wermers (2010), they are committed to 
using cross-sectional data of active fund performance to model research, so as to distinguish the luck and technical components in active fund. Surprisingly, a large part of index fund performance exceeds this simulated distribution, and recent research results show that there is technology in open-ended active fund at least before fee. However, Cremers, Petajisto, and Zitzewitz (CPZ) (2013) point out that even benchmark indexes such as the S \&amp; P500 index can perform abnormally under the standard benchmark model. Therefore, due to the heterogeneity of basic benchmark selection, it is finally identified that there is a technical impact on the performance allocation of active funds in the right tail rather than stock selection or market timing ability. Kosowski et al. (2006) and Fama and French (2010) used self-service method to construct benchmark based 0-A distribution of funds, and then tested the technical situation of active funds. Surprisingly, a large part of the performance of index funds has exceeded the benchmark index, which makes people focus on the technical existence of index funds. In addition, Barras et al. (2010) found that more than $20 \%$ of index funds are technological and their total performance is continuous by using the method of error detection rate under the Fama four-factor model. Cremers, Petajisto, \& Zitzewitz (2013) pointed out that the stock index fund also has excess return a under the Fama four-factor model. Their purpose is to prove that the excess of the index fund exists under the standard model and a series of standard indexes. In the model design, this paper simulates the cpz7 factor model of our country to conduct empirical research. Berk and van Binsbergen (2015) pointed out that the average return of index funds is usually used as a passive benchmark for the performance of active funds, which provides a basis for the discussion of index funds on the research results for the active management performance. If the excess return is a kind of investment skill performance for the active fund, then the performance of the index fund also shows no significant difference from the active fund, then in the index fund, technology also exists.

\section{Theoretical Analysis and Model Construction}

Markowitz put forward that in two portfolios with the same expected rate of return, securities investors will choose the less risky securities to invest, which shows that most investors in the market are risk averse, and concluded that investors who want to obtain higher excess return must bear higher risk In this way, the decentralized portfolio is particularly important for modern investors. Markowitz has built a basic analysis system of mean variance portfolio, which quantificationally uses the expected return weighted average to reflect the return of the portfolio, and uses the standard deviation of return class of each asset in the portfolio to quantitatively describe the risk degree of the portfolio. According to kowitz's portfolio theory, investors can choose different securities to construct portfolio according to their own risk preference and expected asset return. The theory of securities portfolio is based on four assumptions: investors in the securities market are risk averse to risk factors, and tend to pursue the highest 
return at a given level of risk, or the lowest risk at a given level of return; participants in the securities market are based on the expected return rate and standard of securities for portfolio selection, the two represent the expected return level and expected risk level of investors; the whole market is effective and the assets have sufficient liquidity; participants in each market have all the effective information of securities, and the information among all participants is completely symmetrical.

Under such portfolio theory, investors must implement decentralized investment strategy to maximize their own income and minimize their own risk, that is, to reduce the risk by investing their own assets in the securities products of various industries. With the increase of the number of securities in the portfolio, the unsystematic risk of the portfolio is reduced to 0 . At this time, there is only systematic risk left in the portfolio, which is the market risk of the modern securities investment market. When regulating the risk of the whole portfolio, according to Markowitz, the securities industry involved in the portfolio is more irrelevant. Then the risk of the whole portfolio is smaller. In addition, the number of products invested in the portfolio will also have an impact on the overall level of risk, but it is not necessarily the same as the offset effect of the former, because the more products involved in transaction costs and other factors will also have an impact on the income of the portfolio.

According to the predetermined return level, investors can change the type and weight of each security in the portfolio to minimize the total risk level. Under the condition that each expected rate of return determines the portfolio, an investment risk level can be determined. The curve track formed between the expected and variance of all the rates of return is the edge of the effective portfolio. In addition, investors form numerous monotonically increasing convex indifference curves according to their own preference, that is, the risk aversion attribute, which are tangent to the effective boundary of the portfolio. This tangent point is the investment choice made by investors considering all the portfolio returns and risks, which is the core idea of modern portfolio theory.

\subsection{Fama-French Three-Factor Model}

Eugene F. Fama and Kenneth R. French proposed Fama French three-factor model based on CAPM model in 1993. They believed that the most important factors influencing the fund performance level are market return, securities size and book market value. It can be expressed as follows:

$$
r_{i}-r_{f}=\alpha+\beta_{i 1}\left(r_{m}-r_{f}\right)+\beta_{i 2}\left(r_{s}-r_{b}\right)+\beta_{i 3}\left(r_{h}-r_{l}\right)+\varepsilon
$$

The above characters have the same representative meaning as in CAPM model. $r_{i}$ is the return rate of securities asset $i ; r_{f}$ is the risk-free interest rate; $r_{m}$ is the return of market portfolio, $r_{m}-r_{f}$ is the market risk premium; $r_{s}$ is the rate of return obtained by issuing securities assets of small companies, $r_{b}$ is the rate of return obtained by issuing securities assets of large companies; $r_{h}$ is the rate of 
return of assets with high book value of securities assets, $r_{l}$ is the rate of return of assets with low book value of securities assets; $\varepsilon$ is the residual item. The threefactor model describes the impact of three factors on the fund performance scale: the average return level of the securities market, the asset scale of the issuer, and the ratio of the book value of the securities to the market value. The positive and negative coefficients show the preference of the three factors for the fund. In this model, the index reflecting the performance level of the fund is $\alpha$. When the a coefficient is significantly positive, it indicates that the performance level of the fund is better than the overall level of the market, and the investor can obtain positive excess return; when $\alpha$ is significantly negative, it indicates that the performance level of the fund is lower than the overall level of the market, and the investor can obtain negative excess return; when $\alpha$ is significantly zero, it indicates the performance of the fund. The level is basically the same as the overall level of the market, and investors can not obtain excess return.

\subsection{Fama-French-Carhart Four-Factor Model}

The four-factor model was developed by Mark M. Carhart put forward in 1997 that the average return, securities scale, book market value and abnormal return momentum of the securities market are all included in the investigation of the fund performance return level, especially the momentum factor is added, which reflects the investment decision made by the fund managers for the historical factors of the fund investment return level. The model is as follows:

$$
r_{i}-r_{f}=\alpha+\beta_{i 1}\left(r_{m}-r_{f}\right)+\beta_{i 2}\left(r_{s}-r_{b}\right)+\beta_{i 3}\left(r_{h}-r_{l}\right)+\beta_{i 4}\left(r_{u}-r_{m}\right)+\varepsilon
$$

In the four-factor model, the market factor, scale factor, value factor and their coefficients reflect the same economic significance as the Fama French threefactor model mentioned above. The main change lies in the momentum factor, which is obtained by subtracting the poor performance of the previous period from the current return level of the portfolio which performed well in the previous period in the market. The bond portfolio is at its current level of return. Similar to the three-factor model, the a coefficient reflects the ability of the fund to obtain excess return after the adjustment of these four factors. When the a coefficient is significantly positive, it indicates that the performance level of the fund is superior to the overall level of the market, and the investor can obtain positive excess return; when the a coefficient is significantly negative, it indicates that the performance level of the fund is inferior to the overall level of the market, and the investor can obtain negative excess return When $a$ is significantly zero, it shows that the performance level of the fund is basically the same as the overall level of the market, and investors can not obtain excess return. Because the four-factor model is more widely considered than the three-factor model, more scholars think that the model can evaluate the reality of the fund market objectively and effectively, that is, the four-factor model is more widely used in measuring the level of excess return of investment funds. 


\subsection{Self Selected Seven-Factor Model}

Cremers, Petajisto, \& Zitzewitz (2013) recognized that the stock index fund has excess return $a$ under the standard performance model (such as Fama French Carhart), but they proposed to improve the standard model and use a group of indexes as the benchmark to explain the excess return of the fund. They proposed that the difference in the performance of the index fund is due to the benchmark heterogeneity and the index fund industry under the unified index benchmark model. The performance presented is also very different, and the technical component inference of the active fund is improved. The original cremers-petajisto-zitzewitz seven factor model is expressed as follows:

$$
\begin{aligned}
r_{i t}-r_{t}^{f}= & \alpha_{i}+\beta_{1} \mathrm{~S} 5 \mathrm{RF}_{t}+\beta_{2} \mathrm{RMS}_{t}+\beta_{3} \mathrm{R}_{2} \mathrm{RM}_{t}+\beta_{4} \mathrm{~S}_{5 \mathrm{VS} 5 \mathrm{G}_{t}} \\
& +\beta_{5} \mathrm{RMVRMG}_{t}+\beta_{6} \mathrm{R}^{2} \mathrm{VR} 2 \mathrm{G}_{t}+\beta_{7} \mathrm{UMD}_{t}+\varepsilon_{i t}
\end{aligned}
$$

Among them, $r_{i t}$ is the return rate of fund at time $t ; r_{t}^{f}$ is the risk-free interest rate at time $t, \mathrm{~S}_{\mathrm{R}} \mathrm{RF}_{t}$ is the excess return rate of $\mathrm{S} \& \mathrm{P} 500$ index at time $t$, which is equal to the difference between the return rate of $S$ \& $P 500$ index and the risk-free interest rate; $\mathrm{RMS}_{t}$ is the difference between the return rate of Russell mid market stock index and the return rate of S \& P 500 index at time $t$; $\mathrm{R} 2 \mathrm{RM}_{t}$ is the return rate of Russell 2000 index and the return rate of S \& P 500 index at time $t$. The difference between the return of Russell's mid market stock index; S5VS5G $t$ refers to the difference between the return of S \& P 500 value index and the growth index of S \& P 500 at time $t$; RMVRMG R $_{t}$ refers to the difference between the value index of Russell's mid market stock index and the growth index of Russell's mid market stock at time $t, \mathrm{R} 2 \mathrm{VR} 2 \mathrm{G}_{t}$ refers to the difference between the return of Russell 2000 value index and the return of Russell 2000 growth index at time $t, \mathrm{UMD}_{t}$ still refers to the difference between the return of Russell 2000 value index and the growth index at time $t a$ represents the excess return of the fund $i$ adjusted by a series of index factors, and $\varepsilon_{i t}$ represents the residual term of the fund $i$ at time $t$.

According to the cpz7 factor model proposed by Cremers, Petajisto, \& Zitzewitz (2013), combined with China's market situation, this paper also selects nine funds to build a self selected seven-factor model based on the cpz7 factor model, to study the fund's excess return under a series of indexes as the benchmark.

$$
\begin{aligned}
r_{i t}-r_{t}^{f}= & \alpha_{i}+\beta_{1} \mathrm{~S}_{3 \mathrm{RF}}+\beta_{2} \mathrm{Z}_{5 \mathrm{~S}} 3_{t}+\beta_{3} \mathrm{~S}_{8 \mathrm{Z}}+\beta_{4} \mathrm{~S} \mathrm{VSS} \mathrm{G}_{t} \\
& +\beta_{5} \mathrm{Z} \mathrm{VZZ5G}_{t}+\beta_{6} \mathrm{~S}_{\mathrm{VVS}} \mathrm{G}_{t}+\beta_{7} \mathrm{UMD}_{t}+\varepsilon_{i t}
\end{aligned}
$$

Among them: $r_{i t}$ is the yield of fund at time $\mathrm{t} ; r_{t}^{f}$ is the risk-free interest rate at time $t, \mathrm{~S}_{2} \mathrm{RF}_{t}$ is the excess return of CSI 300 index at time $t, \mathrm{ZSS}_{t}$ is the difference between CSI 500 index yield and CSI 300 index yield at time $t, \mathrm{~S}_{2} \mathrm{Z}_{t}$ is the difference between CSI 800 index yield and CSI 500 index yield at time $t$; S3VS3G $\mathrm{G}_{t}$ is the return of CSI 300 value index and CSI 300 value index at time $t$ The difference of 300 growth index return; $Z 5 V Z 5 G_{t}$ refers to the difference of 500 value index return and 500 growth index return at time $t ; S 1 V S 1 G_{t}$ refers to the difference of 800 value index return and 800 growth index return at time $t$, 
$\mathrm{UMD}_{t}$ refers to the momentum factor at time $t$; $\alpha_{i}$ refers to the excess return of Fund $i$ after the adjustment of these series of index factors; $\varepsilon_{i t}$ is shown as the residual term of fund $i$ at time $t$.

\section{Fund's Luck Factor Evaluation Method}

\subsection{Bootstrap Method}

The bootstrap method comes from "bootstrap" in English. The original meaning of English is to pluck boots. People should pluck their own boots, so the bootstrap method means to help themselves. Efron (1979) proposed a method of "resampling" the original sample, that is, "self-service method". The key point is that data processing can be carried out without making specific assumptions on the original overall model and data generation process, without determining the values of all parameters and the probability distribution of all explanatory variables and disturbance items. This method increases the data processing method of small sample size. At present, the bootstrap method has been widely used in the research of practical problems in various fields.

Suppose we want to take a random sample with a sample size of $\mathrm{N}$ from the population. Obviously, this sample from the population must have the information characteristics of the population, and to a certain extent, we can take this sample as the previous population, and then "take a sample with return", and set the sample size to be still $\mathrm{n}$, which is called "self-service sample". Because there are samples put back, there may be repeated observations in the self-service samples, of course, there may not be observations in the original samples. Then we analyze these self-service samples and draw relevant conclusions. The advantage of bootstrap method is that it can obtain many bootstrap samples through computer simulation, and then make statistical inference for the real population situation with these bootstrap samples. The bootstrap method can be seen as the result of continuous sampling from the empirical distribution.

Some examples of bootstrap method. Design and implementation of training organization integrated business management system based on bootstrap Technology. Individual bioequivalence evaluation based on bootstrap method and random weighting method. Performance Evaluation of Probabilistic Methods Based on Bootstrap and Quantile Regression to Quantify PV Power Point Forecast Uncertainty. A bootstrap semiparametric homogeneity test for the distributions of multigroup proportional data, with applications to analysis of quality of life outcomes in clinical trials. New process yield index of asymmetric tolerances for bootstrap method and six sigma approach.

\subsection{Bootstrap Method Simulation Steps}

Taking FFC model as an example, this chapter uses self-service method to distinguish the luck and technical components of fund performance of open-end funds within the limited scope, mainly uses residual self-service method to simulate the luck effect of fund performance, and the specific steps are as follows: 
1) After deducting the risk-free interest rate from the return time series data of fund $i$, we get the excess return $r_{i t}$, and use the FFC model to regress, and calculate residual $\varepsilon_{i t}, \alpha_{i}$ and the coefficient $\beta$ of four factors.

$$
r_{i t}=\alpha_{i}+\beta_{1} \mathrm{MKT}_{t}+\beta_{2} \mathrm{SMB}_{t}+\beta_{3} \mathrm{HML}_{t}+\beta_{4} \mathrm{UMD}_{t}+\varepsilon_{i t}
$$

The estimated coefficients $\left\{\alpha_{i}\right\},\left\{\beta_{1}\right\},\left\{\beta_{2}\right\},\left\{\beta_{3}\right\},\left\{\beta_{4}\right\}$ and the time series $\left\{\varepsilon_{i t}\right\}$ of the residuals are obtained, and then these parameters are saved.

2) Build a simulated fund return rate by using the saved residual, that is, build a self-service sample source for repeated sampling in the next step. For fund $i$, the residual sequence $\left\{\varepsilon_{i t}\right\}$ obtained from the previous step, and the time series $\left\{\dot{\varepsilon}_{i t}\right\}$ with the same number of samples randomly selected, are put back. Then the time series is combined with the original four-factor time series and the correlation coefficients $\left\{\beta_{1}\right\},\left\{\beta_{2}\right\},\left\{\beta_{3}\right\},\left\{\beta_{4}\right\}$ to construct a new fund $i$ s $\hat{r}_{i t}$, that is, the simulated excess return.

$$
\hat{r}_{i t}=\alpha_{i}+\beta_{1} \mathrm{MKT}_{t}+\beta_{2} \mathrm{SMB}_{t}+\beta_{3} \mathrm{HML}_{t}+\beta_{4} \mathrm{UMD}_{t}+\hat{\varepsilon}_{i t}
$$

Using the four-factor model $\hat{r}_{i t}$, we get a new $\hat{\alpha}_{i}$. It can be seen from the model in step 2 above that the construction of $\hat{r}_{i t}$ satisfies the original assumption $\alpha$ is 0 , but for a specific simulation result (according to the self-service samples that can be put back to the repeated sampling), a positive $\alpha$ may appear, because more positive residuals are extracted from the simulation; if more negative residuals are extracted, a negative a may also appear. Therefore, the $\hat{\alpha}_{i}$ sequence obtained by fitting regression based on $\hat{r}_{i t}$ represents the sampling variation when its real value is zero, that is, the value deviating from zero is completely caused by luck, so as to simulate the change of fund's return caused by luck. Because $t$-statistics can alleviate the influence of fund duration and variance individuals, it is measured by a $t$-statistics. In this paper, the $t$ statistic of $\alpha_{i}$ is used for comparative analysis.

3) For all $\mathrm{n}$ funds, follow the above steps to get a sequence $t\left(\hat{\alpha}_{i}\right)^{(1)}(i=1, \cdots, n)$, arrange from large to small, and get $t\left(\hat{\alpha}_{k}\right)^{(1)}(k=1, \cdots, n)$. For all $k_{1}>k_{2}$, there are $t\left(\hat{\alpha}_{k_{1}}\right)^{(1)} \geq t\left(\hat{\alpha}_{k_{2}}\right)^{(1)}$. So far, the first simulation is completed.

4) Repeat the above steps for 1000 times, and then sort all simulation results to form a matrix of $n \times 1000$. $\hat{\alpha}_{1}^{(b)}$ represents the first row and column $b$ in the matrix, which refers to the maximum a value of $N$ funds in the B simulation. According to the lines which indicate the level of excess return of the fund in $n$ funds in this simulation, we can get the percentile numerical distribution that needs to be studied and compared.

So all the values in the first row of the matrix represent the luck distribution of the fund with the best performance, and the $k$ row represents the luck distribution of the fund in the $k$ position.

Therefore, a complete simulation of the fund's luck is carried out.

\subsection{Inference Method}

According to the time series data of each fund, the $\alpha_{i}(i=1, \cdots, n)$ is also arranged from large to small to form $t\left(\alpha_{i}\right) . t\left(\alpha_{k}\right)$ represents the t-value of the em- 
pirical distribution $\alpha$ of the actual excess return sequence of the fund in line $k$. according to the distribution of the above simulation matrix, the average value of each line is calculated and compared with the real value sequence of the empirical distribution.

Because of the implicit assumption in the simulation $\alpha$ is 0 , which means that the income earned by the fund manager through skills can just cover all the expenses and costs incurred by the fund. Therefore, when comparing the mean value of the luck distribution matrix located in the same line with the value of $t(\alpha)$ of the empirical distribution sequence, if the mean value of the distribution matrix $t\left(\alpha_{k}\right)^{\prime}$ is smaller than the actual excess income $t\left(\alpha_{i}\right)$ fitted by the fund, then the actual excess income of the fund means that the fund manager depends on himself According to the distribution of this line in the simulation distribution matrix, the ratio of the value $t\left(\hat{\alpha}_{k}\right)^{(b)}$ obtained in 1000 simulations is smaller than the actual excess return $t\left(\alpha_{i}\right)$. If most of the simulation value $t\left(\hat{\alpha}_{k}\right)^{(b)}$ is smaller than the actual excess return $t\left(\alpha_{i}\right)$, it indicates that the fund managers have indeed obtained the excess return through their own management skills. Similarly, if the mean value of distribution matrix $t\left(\alpha_{k}\right)$ ' is greater than the actual excess return $t\left(\alpha_{i}\right)$ fitted by the fund, it indicates that the fund manager's real excess return can not bear the cost incurred by the fund, and if the majority of the simulated value $t\left(\hat{\alpha}_{k}\right)^{(b)}$ is greater than the actual excess return $t\left(\alpha_{i}\right)$, it indicates that the fund manager does make use of his poor asset management technology to The performance of the fund lags behind the benchmark.

Through the bootstrap method, we can find out the distribution of fund's luck in each percentile of the sample, discuss the influence of fund's luck in this percentile on its excess return change, and get the overall view of how fund managers operate the fund's technology.

\section{Empirical Results and Analysis}

\subsection{Data Sources}

The open-end fund data used in the empirical part of this paper mainly comes from wind Fund database and guotai'an database, including all index fund monthly returns, active fund monthly returns, monthly risk-free returns, monthly market factors, monthly scale factors, monthly value factors, monthly momentum factors and some basic information data of open-end fund.

MKT factor is the weighted index of the market value of all shares; the risk-free interest rate is obtained from the monthly data of one-year deposit interest rate. The construction method of SMB factor is as follows: first, rank the current market value used in June of the current year, and then calculate the difference between the returns of small cap stock portfolio and large cap stock portfolio from July to December of the current year and from January to June of the next year, using market value weighting. The construction method of HML factor is as follows: first, rank the book to market value ratio from June to December of the next year, then calculate the difference between the yield of the 
combination of high book to market value ratio and low book to market value ratio from July to December of the current year and from January to June of the next year, using market value weighting. The construction method of UMD factor is as follows: rank the cumulative yield of the first $2-12$ months every month, calculate the difference between the yield of high-yield stock portfolio and low-yield stock portfolio, the performance cycle of securities assets is 11 months, using market value weighting.

Among them, the index related data used in the self selected seven-factor model is obtained by matching with the original fund data period under the condition that nine indexes exist together and all have monthly return data.

\subsection{Sample Selection}

First, all funds classified as stock type are screened through the China Open-end Fund Database in wind Fund database, and then the funds with an average scale of more than 30 million yuan in their establishment time are selected. 976 equity funds (basic information has been deleted and selected through fund category), then there are 924 funds with the establishment scale of more than 30 million. Each fund must ensure that there are no less than 36 months of monthly return data during the period from its establishment to December 2017 before being selected into this sample. Finally, 230 index funds and 56 active funds are selected. The average size of more than 30 million funds in the time of establishment is an important index for this paper to screen out most funds, which is also the main reason why the data range of this paper is different from that of other articles. Many articles only choose 5-year time span to study the performance of the fund, or randomly choose more than 10 mixed open-end funds for analysis, the universality of the fund is low. Most of the articles choose open-end stock funds and hybrid funds, and rarely include index funds in the discussion of luck component, which is the main innovation of this paper.

This paper finds that under the above conditions, it is mainly index funds, and after manually checking each fund, it is found that ETFs (fully known as exchange traded funds) are also included. ETFs is a composite financial innovation product based on the component stocks of a specific index, which is a fund between open-end funds and closed-end funds, but it is a fully tracked fund So we can also regard it as a passive fund.

Through the selection of this paper, the data period of active funds is from September 2004 to December 2017, and each fund meets the above-mentioned conditions has at least 36 months of monthly data, and the final data volume is 3134 months; the data period of index funds is from December 2002 to December 2017, and the number of index funds under the above conditions is more than that of active funds The final data volume is 17,767 monthly data. The data period of seven-factor index fund is from July 2014 to December 2017, with 9540 monthly data; the data period of seven-factor active fund is from June 2014 to December 2017, with 2252 monthly data. 


\subsection{Descriptive Analysis}

Table 1 shows the basic information of all the funds in this sample database. The total number of funds is 286, including 56 active funds and 230 index funds. There are 20,901 monthly observations in total. According to the classification, the TNA net assets of index funds are 2.045 billion yuan, while the TNA net assets of active funds are 1.384 billion yuan. We can see that generally speaking, the scale of index funds is much larger than that of active funds, and from the number of funds, we can also see that the number of active funds is much smaller than that of index funds after meeting the conditions that the average net assets during the establishment period is more than 30 million yuan Many. Secondly, on the turnover rate and the number of years, it is obvious that the index fund has a larger number of years, while the active fund has a higher turnover rate. As for the Expense ratio, the average Expense ratio of active fund is 0.9

Table 1. Statistical description of sample data.

\begin{tabular}{|c|c|c|c|}
\hline & Mean & Median & Standard Deviation \\
\hline Number of funds & 286 & & \\
\hline Number of active funds & 56 & & \\
\hline Number of passive funds & 230 & & \\
\hline Monthly fund data observation & 20,901 & 69 & 111 \\
\hline Number of funds per month & 115 & & \\
\hline Number of index funds per month & 98 & 65 & 91 \\
\hline \multicolumn{4}{|l|}{ Index Fund } \\
\hline TNA net assets (million) & 2045.349 & 536.408 & 4231.868 \\
\hline Years & 6.7 & 7 & 4.5 \\
\hline Expense ratio (\%) & 0.8205702 & 0.6 & 0.2871156 \\
\hline Turnover ratio (\%) & 0.54 & 0.64 & 0.33 \\
\hline MKT loading & 0.0084151 & 0.0146317 & 0.0786912 \\
\hline SMB loading & 0.0147413 & 0.0119753 & 0.0478572 \\
\hline HML loading & 0.0007849 & -0.0022914 & 0.044368 \\
\hline UMD loading & 0.0005002 & -0.0029176 & 0.0505348 \\
\hline \multicolumn{4}{|l|}{ Active fund } \\
\hline TNA net assets (million) & 1383.557 & 786.9958 & 1684.262 \\
\hline Years & 4.6 & 5 & 4.2 \\
\hline Expense ratio (\%) & 1.712037 & 1.75 & 0.220406 \\
\hline Turnover ratio (\%) & 0.85 & 0.75 & 0.46 \\
\hline MKT loading & 0.0104498 & 0.0156905 & 0.0825392 \\
\hline SMB loading & 0.0142288 & 0.0105032 & 0.051743 \\
\hline HML loading & 0.0023148 & 0.0009942 & 0.0489099 \\
\hline UMD loading & -0.0022328 & -0.0038237 & 0.0500066 \\
\hline
\end{tabular}


percentage points higher than that of index fund, which is also in line with the actual situation. The active fund relies on the stock selection operation of the manager to obtain excess profits, and the management fee paid to the manager will indeed be more.

The gap between the monthly market factor, the monthly scale factor, the monthly value factor and the monthly momentum factor is not very large, because the time span difference is not very long, and most of the two types of funds are overlapped.

\section{4. $t(\alpha)$ Distribution}

Using the self-service method and all the monthly data of the fund, the size distribution of the t-statistics of each excess return under the three models is obtained. Firstly, this paper sets up two databases to separate the data of index fund and active fund. Secondly, according to the monthly return time series data of each individual fund, this paper makes a simple regression, obtains the real excess return of each fund under the empirical method, and sorts the $T$ values of the excess return $\alpha$ of all funds in the two databases, and lists the $T(\alpha)$ values on the $5,10,20,30,40,50,60,70,80,90,95$ percentiles for preparation Line comparison. Then, according to the order of residual bootstrap method in Stata, the monthly return time series data of each individual fund is bootstrap regressed, and the fund excess return under bootstrap method is obtained, and the $T(\alpha)$ value of each percentile is extracted for comparison. Finally, according to the bootstrap method described in the previous research method, we repeatedly sample 1000 times for each fund, and rank the $T(\alpha)$ value obtained from each time to obtain the $T(\alpha)$ matrix of index fund $230 \times 1000$, and the $T(\alpha)$ matrix of active fund $56 \times 1000$. And this matrix is arranged in order of size, so we can directly find the distribution of the values on each percentile in the results of 1000 times of self sampling $t(\alpha)$, and calculate the probability that the value of $T(\alpha)$ under 1000 times of bootstrap method is less than the real value of $T(\alpha)$ obtained by empirical method regression under this percentile. This probability indicates that in this percentile, the excess return of the fund in the fund pool at this level of return exceeds the probability of excess return caused by luck.

In this paper, index fund and active fund are operated separately, and they are compared under three models. Showing in Table 2, the index fund pool, in the Fama four-factor model and the self-selected seven-factor model, the $T(\alpha)$ value of the bootstrap method' There is poor technology in the stock of digital fund, which results in the fund's return below the benchmark. It makes the fund with poor performance $(t(\alpha)$ value $<0)$ get lower excess return because of worse technical performance; it makes the fund with better performance $(t(\alpha)$ value $>0)$ perform worse because of poor technical performance. However, under CAPM model, the results are slightly different. For the $T(\alpha)$ value of index fund with performance level less than $30 \%$, the $T(\alpha)$ value of self-service method is $100 \%$ less than that of empirical method, which shows that in the case of only considering market risk factors, some funds with poor performance in sample base 
Table 2. The distribution of real excess return $t$ (or) of index funds in percentiles and $t$ (or) under self-service method.

\begin{tabular}{cccccccccc}
\hline & & CAPM & \multicolumn{4}{c}{ Fama four factor model } & \multicolumn{3}{c}{$\begin{array}{c}\text { Self selected } \\
\text { seven factor model }\end{array}$} \\
\hline Pct & Sim & Act & Lik & Sim & Act & Lik & Sim & Act & Lik \\
\hline 5 & -1.95 & -1.25 & 1 & -2.11 & -3.37 & 0 & -1.47 & -3.58 & 0 \\
10 & -1.32 & -0.94 & 1 & -1.55 & -2.96 & 0 & -0.97 & -3.19 & 0 \\
20 & -0.85 & -0.65 & 1 & -0.71 & -2.46 & 0 & -0.60 & -2.29 & 0 \\
30 & -0.46 & -0.39 & 1 & 0.24 & -2.06 & 0 & -0.13 & -1.69 & 0 \\
40 & -0.26 & -0.16 & 0.98 & 0.92 & -1.77 & 0 & 0.28 & -1.25 & 0 \\
50 & -0.12 & 0.13 & 0.81 & 1.29 & -1.33 & 0 & 0.73 & -0.79 & 0 \\
60 & 0.18 & 0.26 & 0.578 & 1.65 & -1.00 & 0 & 1.22 & -0.29 & 0 \\
70 & 0.40 & 0.44 & 0.058 & 1.98 & -0.23 & 0 & 1.69 & 0.14 & 0 \\
80 & 0.69 & 0.81 & 0.039 & 2.25 & 0.69 & 0 & 2.34 & 0.62 & 0 \\
90 & 0.98 & 1.23 & 0.04 & 2.66 & 1.61 & 0 & 3.13 & 0.99 & 0 \\
95 & 1.22 & 1.91 & 0.352 & 3.18 & 2.14 & 0 & 3.61 & 1.59 & 0 \\
\hline
\end{tabular}

have obtained more excess returns through the reason of excellent technology of fund managers, and they have exceeded Element of luck. Under the CAPM model, for the fund with poor performance $(t(\alpha)<0)$, the empirical results show that it is generally technical, which makes the performance of the fund with poor performance $(t(\alpha)<0)$ slightly better.

Showing in Table 3, for the active funds, under the three models, the $T(\alpha)$ value of the bootstrap method's excess return on all percentiles is almost $100 \%$ greater than the real excess $t(\alpha)$ value of the sample, that is to say, under the two models, the excess return of the sample fund selected in this paper is lower than the fund's excess return caused by the luck component, that is, when the fund manager selects the index fund stock There is poor technology, resulting in the fund's return below the target benchmark. It makes the fund with poor performance $(t(\alpha)$ value $<0)$ get lower excess return because of worse technical performance; it makes the fund with better performance $(t(\alpha)$ value $>0)$ get lower excess return because of worse technical performance.

\section{Research Conclusion}

\subsection{Enlightenment on the Performance Evaluation of Open-End Funds in China}

From the perspective of the development history of cemetery fund in China, from scratch to gradually strong, at present, the fund products have become an indispensable key investment object in China's securities market. Not only in terms of management scale, performance stability, beneficiary popularity, and even market standardization, China's cemetery fund market has developed rapidly in the past 15 years, which is very important for the development of cemetery 
Table 3. The distribution of real excess return $t(\alpha)$ of active funds in percentiles and $t(\alpha)$ under bootstrap method.

\begin{tabular}{cccccccccc}
\hline & & CAPM & \multicolumn{4}{c}{ Fama four factor model } & \multicolumn{3}{c}{$\begin{array}{c}\text { Self selected } \\
\text { seven factor model }\end{array}$} \\
\hline Pct & Sim & Act & Lik & Sim & Act & Lik & Sim & Act & Lik \\
\hline 5 & -0.61 & -2.21 & 0.017 & -0.77 & -3.43 & 0.001 & -0.36 & -3.79 & 0 \\
10 & -0.48 & -1.94 & 0 & -0.39 & -2.76 & 0 & 0.27 & -3.18 & 0 \\
20 & -0.08 & -1.48 & 0 & 0.39 & -2.23 & 0 & 0.46 & -2.66 & 0 \\
30 & 0.09 & -0.99 & 0 & 0.50 & -1.67 & 0 & 0.61 & -1.97 & 0 \\
40 & 0.19 & -0.75 & 0 & 0.67 & -1.50 & 0 & 0.83 & -1.72 & 0 \\
50 & 0.32 & -0.30 & 0 & 1.10 & -1.11 & 0 & 1.38 & -1.37 & 0 \\
60 & 0.86 & -0.18 & 0 & 1.40 & -0.68 & 0 & 1.56 & -0.89 & 0 \\
70 & 1.01 & -0.08 & 0 & 1.66 & -0.53 & 0 & 1.94 & -0.66 & 0 \\
80 & 1.55 & 0.07 & 0 & 2.05 & -0.34 & 0 & 2.74 & -0.51 & 0 \\
90 & 1.98 & 0.44 & 0 & 2.81 & 0.43 & 0 & 3.25 & -0.30 & 0 \\
95 & 2.31 & 0.53 & 0 & 3.52 & 0.84 & 0 & 3.74 & 0.36 & 0 \\
\hline
\end{tabular}

fund It is particularly important to understand the real performance of open-end funds in China, not only for investors, but also for fund companies to design relevant fund products.

First of all, we discuss the fund's luck distribution in each percentile through the bootstrap distribution of the t-statistics of the fund's excess return in three models. Generally speaking, both index fund and active fund have technology in each percentile, otherwise, the bootstrap distribution of $T(\alpha)$ should be close to 0.5 , but the empirical results show that there are two kinds of funds due to the foundation Gold manager's inferior technology has pulled the fund returns that could have obtained higher returns by luck to a lower position, resulting in excellent funds not getting as much excess returns as they should have obtained, and resulting in worse performance of funds. In this case, it is suggested that fund managers should improve their own quality, learn more theoretical knowledge and exercise their skills of judging the market. It has some enlightenment to the training and education of fund market practitioners in China.

Finally, the reason of luck will lead to the outstanding performance or poor performance of some funds in China's open-end fund market, but the luck factor is not sustainable. In this paper, the persistence of the fund is also studied to some extent, which shows that some funds are persistent, which further proves that the super high excess return of the fund is due to the high technology of the manager, or The current negative return is also due to the bad technology of managers, which also shows that the fund market in China is an imperfect market, especially in terms of market effectiveness, which also provides investors with more investment ideas and guidance significance when they invest in funds. Without supporting the hypothesis of effective market, fund managers with ex- 
cellent technology can win the market, and the proportion of poor technology held by fund managers is also small. For some individual investors and institutional investors who adopt conservative financial management, they can put some assets into index funds or active funds with better historical performance in order to obtain higher excess return.

\subsection{Suggestions and Improvements}

According to the empirical content and analysis results of this paper, suggestions will be provided to the participants of the open-end fund market to obtain the healthy and healthy development of China's securities market. Mainly for the fund investors, fund companies and fund regulators to propose three groups.

First of all, fund investors are the most vivid driving force of the fund market. They are the suppliers of funds and the demanders of fund products in the whole fund market. It is precisely because of the existence of fund investors that the fund market is born. Only when fund investors continuously inject funds and outflow funds can the fund market be full of vitality. Compared with the situation of foreign developed countries, the development of open-end fund market in China is not perfect, and the system is gradually mature, but the main force of fund market-the overall quality training of investors is not mature, and the attitude and basic knowledge education of investment need to be further improved. Through the empirical part of this paper, we can see that the real return of more than half of the fund products in the fund market is greater than zero. When investors choose a fund product that matches their investment philosophy and expected return, they should fully understand the risk of the product and whether they can bear the risk. In the pursuit of excess return, we should also make clear the risk level of products, and do not produce wrong estimates. Further, investors should not only judge the fund products based on the recent earnings, but also take full account of the luck component, identify its real ability, be good at finding the fund products with positive excess earnings but currently underestimated, and then select the right fund products. Correspondingly, we should pay more attention to the long-term performance when judging the fund return level. Due to some unexpected factors, the technical level of the fund managers may change, leading to the fluctuation of the fund performance level. Therefore, in the case of not knowing the actual technical level of the fund managers, and according to the empirical part of this paper, it is in the top five The outstanding funds listed in the list are of sustainability, so investors need to know more about the long-term performance level of the fund when they purchase the fund.

Secondly, fund companies play a leading role in the design of fund products in the fund market, and play a key role in the income level of the fund. For the fund companies in foreign developed countries, China's fund companies may be relatively immature, and it is not appropriate to apply some foreign experience directly, or it should be based on the specific situation of China Body analysis. It is suggested that fund companies should pay more attention to the true technical 
level of fund managers when evaluating the fund products within the company, rather than only considering the recent performance of the fund. Because of luck, the poor performance of the fund does not indicate the technical fault of the fund managers. Similarly, the technical fault of the fund managers. The fund may show outstanding performance due to the good luck of the fund. Therefore, fund companies should increase the investigation of the long-term performance of fund performance and establish a more comprehensive and authentic fund evaluation system. And when designing products and making asset portfolios, we should consider the influence of accidental factors and pay more attention to the long-term profitability of fund products. In addition, when introducing the products to investors, the fund company's business personnel should fully prompt and objectively introduce the existence of the fund's return contingency factors, and comprehensively and completely introduce the potential risks to investors. They should not blindly only sell the fund products, but conceal some risk factors, not to mention guarantee the return rate to investors.

Finally, for the fund supervision department, the fund supervision department, as the main body of the rule-making of the whole securities investment fund market, plays an important role in regulating the operation behavior of the main body of the fund market, supervising the operation of the fund company and protecting the rights and interests of investors. In recent years, the continuous sound and healthy development of the open-end fund market benefits from me China's fund market norms continue to improve, the effective supervision of the fund regulatory authorities, the timely introduction of rules and regulations. China's fund market regulatory departments mainly include the government regulatory department-China Securities Regulatory Commission; the exchange-Shanghai Stock Exchange and Shenzhen Stock Exchange; and the self-regulatory organization of the fund industry-China Fund Industry Association. When making relevant policies, China Securities Regulatory Commission should take into account the real performance of open-end funds in China, not only the overall performance level of open-end funds, but also the influence of luck factors and other social environmental factors, which will promote China Securities Regulatory Commission to make relevant policies and enact laws and regulations more pertinently Solve relevant practical problems. For the exchange, when publishing the market price of investment fund products, it should accurately disclose the true performance level of the fund after stripping the fund's luck component in the relevant disclosure, and strictly restrict the access conditions of products in the fund market according to the level. And in the evaluation of the fund's performance, we should also be fair and open, objective and true evaluation of the fund. As for China Fund Industry Association, it is necessary to strengthen the supervision of fund management companies, fully consider the influence of accidental factors when propagating and introducing products in the industry, show the real income of fund products, and prohibit funds. 


\subsection{The Limitation of Research}

First of all, this paper does not do the balance panel processing for the monthly data screening of funds, and generalizes the monthly data of funds with different time periods and lengths, which may lead to some systematic errors not taken into account in the data processing, and thus has little effect on the time interval to limit. Secondly, in the case of limited fixed year with the same length of monthly fund data, the fund data in the range is less, and the optional data range is narrow. The cemetery fund market in the United States has developed very well, whether the quality of fund products or the quantity and quality of fund return data are relatively high, which may lead to deviation when using the same method to deal with the specific data of China's fund market. Finally, the time range and data volume of the self selected seven factor model are also relatively narrow. The use of this model to explain fund performance is not as strong as the foreign CPZ seven factor model, which is only a reference in this paper, but also needs to be revised and adjusted to strengthen its interpretation of the Chinese market. In the future, this paper will improve these aspects of the article and constantly improve the content of the whole article.

\section{Conflicts of Interest}

The author declares no conflicts of interest regarding the publication of this paper.

\section{References}

Barras, L., Scaillet, O., \& Wermers, R. (2010). False Discoveries in Mutual Fund Performance: Measuring Luck in Estimated Alphas. Journal of Finance, 65, 179-216. https://doi.org/10.1111/j.1540-6261.2009.01527.x

Berk, J., \& van Binsbergen, J. H. (2015). Measuring Skill in the Mutual Fund Industry. Journal of Financial Economics, 118, 1-20. https://doi.org/10.1016/j.jfineco.2015.05.002

Brinson, G. P., Hood, L. R., \& Beebower, G. L. (1986). Determinants of Portfolio Performance. Financial Analyst Journal, 42, 39-44. https://doi.org/10.2469/faj.v42.n4.39

Carhart, M. M. (1997). On Persistence in Mutual Fund Performance. Journal of Finance, $52,57-82$

Chang, E. C., \& Lewellen, W. G. (1984). Market Timing and Mutual Fund Investment Performance. Journal of Business, 57, 57-72. https://doi.org/10.1086/296224

Cremers, M., Petajisto, A., \& Zitzewitz, E. (2013). Should Benchmark Indices Have Alpha? Revisiting Performance Evaluation. Critical Finance Review, 2, 1-48. https://doi.org/10.1561/104.00000007

Efron, B. (1979). Bootstrap Methods: Another Look at the Jackknife. The Annals of Statistics, 7, 1-26. https://doi.org/10.1214/aos/1176344552

Fama, E. F. (1972). Components of Investment Performance. The Journal of Finance, 27, 551-567. https://doi.org/10.1111/j.1540-6261.1972.tb00984.x

Fama, E. F., \& French, K. R. (1993). Common Risk Factors in the Returns on Stocks and Bonds. Journal of Financial Economics, 33, 3-56. https://doi.org/10.1016/0304-405X(93)90023-5

Fama, E. F., \& French, K. R. (2010). Luck versus Skill in the Cross-Section of Mutual 
Fund Returns. The Journal of Finance, 65, 1915-1947.

https://doi.org/10.1111/j.1540-6261.2010.01598.x

Henriksson, R. D., \& Merton, R. C. (1981). On Market Timing and Investment Performance. II. Statistical Procedures for Evaluating Forecasting Skills. Journal of Business, 54, 513-533. https://doi.org/10.1086/296144

Kosowski, R., Timmermann, A., Wermers, R., \& White, H. (2006). Can Mutual Fund Stars Really Pick Stocks? New Evidence from a Bootstrap Analysis. Journal of Finance, 61, 2551-2595. https://doi.org/10.1111/j.1540-6261.2006.01015.x

Sharpe, W. (1966). Mutual Fund Performance. Journal of Business, 39, 119-138. https://doi.org/10.1086/294846 